\title{
Semilleros de Investigación en Colombia, Chile y Brasil: encuentros pedagógicos, experiencias y acciones de r-existencias en la formación docente
}

\author{
Fátima Lucília Vidal Rodrigues* \\ Silvia López de Maturana Luna** \\ Blanca Nelly Gallardo Cerón ${ }^{* * *}$
}

\section{Resumen}

En los últimos cinco años se ha llevado a cabo la experiencia transformadora de los semilleros de investigación en Colombia, Chile y Brasil, enfocada a la formación docente de jóvenes universitarios, la creación de espacios de investigación con la infancia y la práctica transformadora de su territorio, tres realidades diferentes y con propuestas de acción vinculadas a las Universidades y a las acciones de promoción de otras r-existencias en nuestra Abya Yala. El objetivo principal de este artículo es compartir las diferentes experiencias de formación docente, surgidas del encuentro intercultural de profesores y estudiantes universitarios, que deseaban ofrecer un espacio alternativo a los planes de estudio y a la investigación académica. El texto presenta, pues, el registro de estas acciones y el camino indirecto que permite encuentros pedagógicos transformadores y prácticas decoloniales, que apoyan la comunalidad de los hechos y, paradójicamente, sus singularidades.

\section{Palabras clave}

Semilleros de investigación, interculturalidad, formación de profesores, acciones de r-existencias.

Recepción original: 31 de marzo de 2021

Aceptación: 2 de mayo de 2021

Publicación: 1 de julio de 2021

Es como inaugurar otro tiempo, otro futuro, es decir, otro mundo en que todos puedan vivir dignamente

Bautista, 2014

Hasta que la dignidad sea haga costumbre Hernández, 2017

Los Semilleros de Investigación se constituyen, como movimiento desde 1996-1997, en una estrategia extracurricular para fomentar la investigación en las universidades colombianas. El hito fundacional se construye por estudiantes y docentes colaboradores de la Universidad de Antioquia quienes conjuntamente con la Universidad de Caldas y del Cauca se integran para crear los primeros escenarios de semilleros con trabajo en Red, como el encuentro nacional de semilleros realizado en Manizales en el año 1998. Desde entonces, más de doscientas Universidades en Colombia cuentan con grupos de Semilleros, los cuales se constituyen en diferentes formatos y siguen el principio de ser «un espacio para tejer red, construir conocimiento y edificar sociedad» (Pineda apud Gallón, 2009, p. 6). Cada semillero tiene su propia organización, dinámica y procedimientos internos y, al igual que en Chile (desde 2008) y Brasil (desde 2015), se destaca

${ }^{*}$ ) Profesora de la Universidade de Brasília. Dirección electrónica: vidalrodrigues@yahoo.com.br

$\left({ }^{* *}\right)$ Profesora de la Universidad de La Serena (Chile). Dirección electrónica: silvialml@gmail.com

$\left.{ }^{(* *}\right)$ Profesora de la Universidad Católica de Oriente (Colombia). Dirección electrónica: bngallardo@gmail.com 
por la colaboración entre pares, el interés en la producción de conocimientos y la transformación social.

Los Semilleros de Investigación que presentamos a continuación son proyectos de comunalidad, de Bien Vivir, orientados a la investigación formativa desde el aprender investigando que contribuye a la formación de docentes y jóvenes universitarios, con aporte reflexivo a la didáctica desde la creación de espacios de investigación con la infancia y a la práctica transformadora de su territorio educativo. Con base en una pedagogía decolonial, que convoca a los saberes subordinados para desestabilizar las prácticas existentes del saber y del ser, las acciones de r-existencias ocurren en la vida cotidiana, como un verbo, en acciones ligadas a las comunidades, a las escuelas, a la infancia y al conocimiento. Dicho de otra manera: el Semillero representa la posibilidad de reconstruir, desde la condición de dignidad, el conocimiento, la vida y la autodeterminación como una semilla que crece y resiste.

Según Walsh (2017), nuestro desafío es decolonizar e interculturalizar las instituciones y las estructuras fijas y rígidas con las que vivimos. Nuestros movimientos colectivos apuntan a una formación basada en esta perspectiva, que permita a los estudiantes sentir la experiencia de la interculturalidad como un pensamiento-acción, como una práctica de frontera, que refuerza la esperanza que es necesaria no por obstinación, sino por exigencias históricas y existenciales. Las profesoras Candau y Russo (2010, p. 166) advierten que «la interculturalidad se concibe como una estrategia ética, política y epistémica» y de ahí que el encuentro de los semilleros colombianos, chilenos y brasileños significa una estrategia que deconstruye parámetros universales y pone en jaque la lógica formativa guiada por el conocimiento único. Desde esta perspectiva, los procesos educativos son fundamentales para el cuestionamiento de la colonialidad formativa y la promoción de acciones de convivencia, vinculadas o no a las acciones de extensión universitaria. La perspectiva intercultural representa, por lo tanto, la ruptura con las dicotomías asimétricas, con las designaciones del otro; con la colonización del ser, del poder, del conocimiento y de la vida humana y de las naturalezas.

Los semilleros de investigación en Colombia, Chile y Brasil se encuentran para repensar las prácticas pedagógicas y posibilitar una formación docente comprometida con el cambio ético y educacional en Latinoamérica. Dicho esto, ahora sigue una descripción reflexionada acerca de nuestros trabajos, con la intención de compartir acciones y sueños.

\section{Creación y proyección del Semillero de investigación Akará- Colombia ${ }^{1}$}

Cuando pienso me convierto en lo que pienso Serres, 2015

Colombia a finales del siglo xx desarrolló acciones políticas enfocadas a pensar en nuevo milenio. Se contó con orientaciones elaboradas desde un grupo de trabajo conocido como Misión de Sabios, formaban parte investigadores reconocidos, escritores y miembros de la academia que dejaron, en el texto Colombia al filo de la oportunidad (1994),

(1) El escrito se construye desde la Investigación Impacto de los semilleros de Investigación. Nodo Antioquia Colombia. 
diferentes propuestas que incorporaban como la formación en ciencias desde la infancia con la declaración Hacer endógena la ciencia en la cultura. Los estudiantes colombianos universitarios crearon entre los años 1996-1997, la estrategia de investigación formativa de una comunidad de práctica investigativa, una importante ruta para movilizar relevo de comunidad de investigadores desde la infancia hasta el pregrado, un hito en la educación, gestado por un colectivo de estudiantes acompañados de docentes, que tomó el nombre de Semilleros de Investigación.

La emergencia de los semilleros de investigación, como comunidades de aprendizaje, avanza hacia comunidades de práctica, con estudiantes y docentes en debate sobre la formación académica, la investigación y la enseñanza de las ciencias (Martínez et al., 1989). Es evidente que estaban orientadas desde las estrategias formativas de la época, marcadas por las prácticas instruccionales, tradicionales desde la cátedra de metodología de investigación y otras articuladas al proceso curricular, así como la práctica investigativa desde grupos de investigación que convocaban a los estudiantes auxiliares de investigación para apoyar las labores logísticas de los investigadores titulares docentes.

En este contexto, surgieron las primeras formas de semilleros como congregaciones de estudiantes y docentes que voluntariamente y, en su tiempo libre, comenzaron a desarrollar prácticas investigativas de forma autónoma al interior de las universidades. Estos colectivos fueron tomando características específicas como: la prevalencia de la voluntad y el compromiso y el gusto por la práctica investigativa y el trabajo en Red², todo lo que construyó con el tiempo una estrategia de formación investigativa, con amplia capacidad de fortalecimiento y proyección hacia todo el territorio nacional.

Tras más de dos décadas de su creación, los semilleros de investigación son referente internacional como un espacio-tiempo alternativo, que gesta condiciones para una educación a través de la práctica investigativa. No cabe duda que es una plataforma de formación social y ciudadana en el marco de la perspectiva crítica con la apropiación del conocimiento, construido mancomunadamente para el ejercicio participativo desde el saber en los contextos.

\section{Génesis de Akará: alma y sentido de ser semillerista}

En el año 2002, estudiantes de la Universidad Católica de Oriente (Antioquia, Colombia) se unieron a las iniciativas de formación de los primeros semilleros de investigación en la región afectada por el conflicto armado. Se comenzaron a crear redes y las condiciones para la creación del Semillero Akará como lugar de investigación en arte y cultura.

Los orígenes del semillero Akará emergen con estudiantes dedicados a la investigación en arte y cultura. Estuvieron apoyados por docentes de trayectoria académica, con quienes se congregaron alrededor de un proyecto de investigación sobre el ensayista Baldomero Sanín Cano, interés al cual se articulan los estudiantes de la Universidad de Antioquia, representantes de la Universidad Pontificia Bolivariana y personas sin vínculo institucional. De este modo, se crearon las condiciones de un semillero interinstitucional para continuar los procesos de investigación con nuevos actores (Montoya-Rodas, 2016). En el 2006, los semilleristas avanzan en investigación y acciones sociales y, por

(2) Espacio de Red se refiere a articulación de personas naturales y jurídicas integrados alrededor del interés de investigación formativa y formación en investigación. 
consiguiente, decidieron oficializar el nombre a semillero interinstitucional Akará (Significa Alma en legua Katio de las comunidades indígenas del territorio). Su creación se tiene que entender como la posibilidad de establecer un escenario de investigación sobre temáticas relacionadas con el conflicto que se vivía en este momento en el Oriente Antioqueño y los diferentes intereses relacionados con el arte $y$, al mismo tiempo, con la cultura en la región.

El semillero está vinculado a la Red Colombiana de semilleros de investigación (RedCOLSI), algo que permite la articulación de akaritas en los procesos administrativos de dicha institución, con ellos la voz y la perspectiva crítica, se integran en las formas de agenciamiento de la Red. Queda reflejado de la siguiente manera: desde el ocupar cargos con roles de coordinación regional, control interno nacional, hasta ocupar lugares de reconocimiento nacional e internacional como gestores de células de apoyo a las infancias y juventudes investigadoras en Colombia y América.

La llegada de actores desde diferentes instituciones también congregó más fuerza para adelantar procesos de interacción que se desarrollan dentro del semillero y en la región del Oriente Antioqueño, como son la lectura crítica, la apropiación de espacios, la organización y realización de eventos relacionados con el arte, encuentros de celebración alternativos en homenaje a los niños y la mujer entre otros. Todo lo anterior moviliza los intereses de los semilleristas hacia procesos investigativos con posibilidad epistémica desde diversos lugares de contemplación del contexto y al surgimiento del proyecto de investigación a través de la cartografía que permite conocer y describir los espacios para el ejercicio artístico y los actores nativos del territorio. Un ejemplo de todo ello es la creación del festival Soy ArteNativo.

Con la comprensión del arte y la investigación como los dos factores determinantes en la transformación cultural, las líneas de acción que se trabajan en el Semillero son las siguientes:

1. Investigación. Es cuando integrantes pioneros del semillero eligieron objetos y fenómenos de estudio para sus investigaciones de formación profesional, con temáticas relacionadas con perspectivas teóricas y filosóficas derivadas de los debates en el semillero. Destacamos los trabajos de investigación dirigidos a comprender las comunidades artísticas y educativas.

2. Acción. El semillero parte de una comunidad de colectivos que configuran un territorio de práctica investigativa con objetivos de acción en sus procesos de formación y de interacción con los contextos que les permiten pasar de ser estudiantes pasivos, a ser semilleristas investigadores, activos e integrados en red como actores dinámicos en los territorios. De este modo, se constituye una nueva realidad, donde se transita de la acumulación de experiencias a las estrategias que movilizan la formación de comunidad científica y la construcción de nuevos saberes para la ciencia y el desarrollo del sujeto.

En este sentido, Akará contribuye a partir de prácticas investigativas, como las de muchos semilleros de investigación en Colombia, a generar las condiciones para ir avanzando hacia la conformación y posicionamiento de un agente político no esperado en el país, es decir, el semillero de investigación.

Como espacio de interacción, el Semillero Akará se creó, integrado por estudiantes que se reúnen de forma voluntaria, con un compromiso de estudio y abordaje investi- 
gativo de temas de su interés respecto al arte y la cultura. Con ello, se promueven posibilidades de formación del relevo generacional de comunidad científica desde la investigación-creación para el país. Adquiere con el ritmo de sus actividades, características fundamentales de la horizontalidad como forma de relacionamiento entre docentes de apoyo y estudiantes semilleristas, en condiciones de interlocución válida, para la construcción de nuevos saberes.

Asimismo, la voluntad entra a tomar fuerte relevancia, entendida como el deseo que mueve la participación estudiantil, unida a sus intereses y al reconocimiento de su capacidad como actor y generador de obras, derivadas de actividades asumidas como responsabilidad con el semillero y con compromiso respecto de los objetivos investigativos.

Todos los integrantes del Semillero Akará están implicados en procesos de autoformación desde la práctica investigativa, que contribuye al desarrollo de la autonomía como la «capacidad de acción, partir de lo determinado por la estructura, hacerse consciente de lo que le han asignado, para poder encontrar posibilidades de acción» (Zemelman, 2007, p. 72) así como también reconocen la fortaleza que conlleva para este mismo proceso, el trabajo en equipo, todo lo cual aporta al desarrollo de la capacidad de agencia, en tanto administrador de sus potencialidades y capacidades para el desarrollo de alianzas estratégicas que permiten posicionarlo en las siguientes comunidades: científica, académica, artística, educativa y laboral.

Consideramos que el nuevo ciudadano akarita trae consigo características fundamentales de un profesional con valor agregado derivado desde la investigación formativa, que le convierte en un actor y constructor de su ideal profesional. No cabe la duda que es la figura del hombre libre planteada por Freire (1972), como ser construido por la cultura y la historia con posibilidad de libertad en la interacción y diálogo con los otros. Un sujeto que forja sus expectativas de participación en las comunidades, con el acercamiento a los territorios a través de las investigaciones, o nuevas formas de trabajo desde sus convicciones y acercamientos al saber.

Derivado del Semillero Akará, se crea en el año 2006 la Corporación Alma Arte y Acción, una organización no gubernamental que comienza a actuar en alianza estratégica con las universidades y la RedCOLSI, para dar continuidad a todas las estrategias desarrolladas y apropiadas en los escenarios de semilleros de investigación. Se crean programas para apoyar el desarrollo desde la primera infancia, nuevos semilleros de investigación e investigaciones de alcance nacional e internacional. Al cierre del año 2018, destacamos que la Corporación cuenta con cuatro semilleros que llevan inherente la convicción de investigación como estrategia de formación de juventudes e infancias generadoras de saber y representantes de otras formas de ciudadanía no esperadas, pero que llevan en sí el ideal de los objetivos educativos de desarrollo de la autonomía y el gusto por el estudio y la investigación.

En el año 2019, un hito marca la historia del semillero de investigación, el surgimiento de un proyecto de Educación alternativa denominada Áurea, el cual entra a jalonar procesos de interacción nacional e internacional alrededor de la formación alternativa. Los estudiantes formados desde la infancia en el Semillero Akará, ya como profesionales de la educación, con toda la experiencia acumulada y movidos por la convicción de atender una demanda en el territorio de proyectos de educación alternativa, ponen en oferta una educación básica primaria y secundaria con formas de trabajo 
en colectivo, con investigación solidaria relacionada con los fenómenos y vinculación del trabajo desde investigación o conectada con redes de apoyo a la educación alternativa en el ámbito nacional e internacional.

La forma como los semilleristas se apropiaron la práctica investigativa, da cuenta de una juventud no esperada en los escenarios educativos y sociales, una que se aleja de los roles tradicionalmente asignados a los jóvenes y a las infancias, ubicados desde el pensamiento occidental en el lugar de la rebeldía, el hedonismo y el consumo acelerado. Los semilleristas se convierten en participantes activos en la construcción de saberes alrededor de los fenómenos y problemas de los territorios y, de esta manera, asumen desde la voluntad y el interés la posibilidad de dar continuidad a procesos con formación social.

Se puede evidenciar que los semilleros de investigación consolidaron una estrategia que permite la reflexión crítica y aportar un ideal de ciudadano comprometido con sus procesos de formación. Se apropia, desde la acción, rutas de autoformación con participación colectiva que pone en tela de juicio la educación tradicional.

\section{Semillero de investigación de la carrera de Pedagogía en Educación Parvularia de la Universidad de La Serena-Chile}

El Semillero de Investigación de la carrera de Pedagogía en Educación Infantil de la Universidad de La Serena (SIEP-ULS) es una instancia de educación no formal que nace en el año 2008, a través de la práctica pedagógica, social, política y cultural de un grupo de doce estudiantes y una profesora, y crece como acción de resistencia a las prácticas escolarizantes de los espacios universitarios. Lo inspira no solo la necesidad de cambiar las interrelaciones jerarquizantes de las prácticas pedagógico-culturales sino también la posibilidad de contribuir, desde los espacios y tiempos universitarios, a transformar los dispositivos de desigualdad hacia los grupos más desposeídos de la sociedad.

Cabe destacar que se inspiró en los semilleros colombianos, y surgió a la vida con otra manera de operar, pero con finalidades similares, la de ofrecer a los y a las estudiantes la posibilidad de formarse como sujetos reflexivos/as, críticos/as e investigadores/as en la acción. Nuestro Semillero, junto con la posibilidad de recibir a estudiantes de otras carreras, se mantiene en la carrera de Educación Parvularia (Educación Infantil) porque consideramos que la infancia, como señala Hannah Arendt (2001), es el lugar en el que nacen los salvadores del mundo, donde todo allí puede suceder y todo aun es algo por construir. El Semillero entiende la educación como promesa de futuro y un proyecto para incrementar la humanidad, eso nos motiva para construir posibilidades de mirar la vida a través de los ojos de asombro, curiosidad, entusiasmo e intensidad de la infancia.

Sus integrantes se denominan Semillas para connotar la potencia de algo fuerte que se siembra, crece y se desarrolla en plenitud hasta dar buenos frutos, para lo cual se necesita abonar una tierra fértil para que accedan a su crecimiento y desarrollo.

\section{Sentido}

Las/os semillas intentan descolonizar las subjetividades para revertir, en parte, los efectos del aparato escolar que se sostiene en una gramática de poder que jerarquiza la distribución de los saberes y pavimenta el camino para la exclusión de los más débiles. 
También intentan asumir la ciudadanía de manera crítica, como acto pedagógicopolítico que les posibilite comprender las estructuras deshumanizantes de la sociedad. Una manera de hacerlo son las lecturas y los análisis permanentes de la contingencia antes de iniciar una sesión, la observación, los cuestionamientos, los debates, la investigación permanente en la acción y la relectura del mundo en el que están inmersas. Se lanzan, pues, a la incertidumbre, a explorar el territorio (sin perder el mapa) sin saber qué va a pasar o con quiénes se van a encontrar en ese salto hacia la errancia (Serres, 1999). Eso posibilita el entendimiento y la construcción social de cada semilla como sujetos posicionados dentro de un proyecto de alteridad permanente.

Las/os semillas crean condiciones para buscar otras maneras de ser y estar en los espacios universitarios, donde se dan cuenta de las muchas maneras de comprender el mundo, para no quedarse siempre igual a sí mismas. Se proponen perder el miedo a hacer cosas distintas, salir de sus lugares cómodos, ocupar tiempos a los cuales les es difícil acceder, y liberarse de las cadenas de la escolarización. Un ejemplo: en las conversaciones cotidianas del Semillero se analiza, por una parte, la poca o nula implicación de muchos estudiantes en las tareas ciudadanas, la artificialidad de los compromisos asumidos y las prácticas docentes inhibidoras de aprendizajes genuinos, llegando a la conclusión que esas son repercusiones de una sociedad que ha despolitizado lo cotidiano. Por otra parte, se reconocen los procesos de alteridad como senderos de respeto y legitimidad de los otros y las otras, pensados de manera crítica como acto pedagógico-político que permitan humanizar a la sociedad. Desde allí surgen líneas orientadoras para la acción.

El Semillero se reconoce como un alumnado con derecho de aprender a re-leer su cultura, sobre todo en momentos de cambios tan acelerados en una sociedad presa de las nuevas tecnologías, que exigen estar conscientes del rol de ciudadanos/as pensantes y sintientes que a cada uno/a le compete. En las reuniones y conversatorios, se asumen como sujetos políticos que abordan el problema educativo desde una perspectiva crítica y no entran en el juego del sometimiento institucional que generalmente le lleva a acomodarse ante los cambios tecnocráticos que reducen los procesos educativos a un entrenamiento técnico suficiente para reproducir las incongruencias escolarizantes.

Así, como los niños y las niñas, las semillas pueden establecer relaciones complejas si solo dejamos que fluyan y se desparramen por los entornos que las circundan, porque conforman totalidades sinérgicas cualitativamente diferentes a una enseñanza unidireccional y dicotómica que inhibe e inferioriza. En el semillero se activa el gusto por explorar, experimentar, relacionar y equivocarse, a costa de alegrías y de desilusiones, para que no se sometan y no reproduzcan tácitamente lo preestablecido perdiendo su propensión creadora.

\section{Propósitos}

Uno de los principales propósitos es el de conformar un grupo de investigadores/as de la cultura que parta del deseo de saber de sus integrantes $y$, desde allí, orientar sus inquietudes e intereses a partir del debate, lectura, preguntas, argumentaciones y acción. Recordamos que esta práctica surgió al preguntarnos si, como docentes, estábamos formando a nuestros/as estudiantes desde su propensión a aprender y si estábamos considerando el relevo generacional. Para enriquecer y activar la propuesta propusimos trabajar la autonomía, la autoconfianza, la motivación de logro, el trabajo colabo- 
rativo y la autogestión. Así como también considerarla como una alternativa de indagación para la formación de nuevos investigadores/as.

Otro propósito es reconocer el sentido democrático y ciudadano de la educación para evitar, como señalan Rodari (2016) y Cortina y Conill (2001) respectivamente, que nadie sea esclavo ni súbdito de un sistema. Es, por ello, que se persigue la formación crítica para distinguir entre una ciudadanía funcional al sistema dominante y una ciudadanía que responda a un proyecto político de descolonización, emancipación, y creación, lo que requiere de la transformación de sus propias estructuras y relaciones sociales.

Por último, añadimos la tarea de descubrir, fortalecer y compartir la potencialidad de los y las estudiantes, el desarrollo del pensamiento crítico y la curiosidad epistemológica, para que se formen como investigadores/as educadores/as de múltiples disciplinas, fortalezcan los lazos afectivos y el compromiso del saber académico especialmente gracias al trabajo comunitario. Creemos que esa es una manera de revertir el perverso efecto del colonialismo cognitivo que se ha impregnado en las mentalidades y subjetividades desde la temprana edad y que sigue reproduciéndose de manera endógena. Se intenta lograr, por tanto, una Pedagogía de las presencias, para mostrar que lo que no existe sí que está allí y también es. Es un objetivo que intenta transformar lo ausente en presente. Por ejemplo, visibilizar la infancia, rescatar el valor de las comunidades, desafiar el orden establecido.

\section{Integrantes y funcionamiento}

Generalmente, la cantidad de integrantes bordea una media de doce estudiantes, a pesar que, desde el primer año de ingreso a la universidad se les invita a participar. Luego, se les describe la intención y se les comenta el sentido del Semillero, sobre todo que se les necesita. Se les hace notar que no hay recompensas materiales ni notas, calificaciones o puntajes, pero que en esos espacios y tiempos encontrarán muchas razones para sentirse ciudadanas/os activas/os en la transformación hacia un mundo más justo y equitativo. Huelga destacar que, una vez que aceptan ingresar voluntariamente, su nivel de responsabilidad y compromiso es admirable. A pesar de la poca cantidad de sus integrantes impactan en la formación universitaria a través de las experiencias educativas y comunitarias y por las maneras en que desarrollan la autonomía y la generación de propuestas de acción.

Las/os semillas se reúnen semanalmente $y$, con quien coordina académicamente, cada quince días quien se integra de manera horizontal de responsabilidad compartida para la toma de decisiones a través del conflicto, diálogo y consenso. Cada proyecto cuenta con un equipo de trabajo de acuerdo a las acciones a realizar, las que generalmente son de participación en actividades inclusivas y democráticas, realización de actividades de autogestión y conformación de redes de trabajo.

\section{Organización y participación de experiencias}

Son espacios y tiempos que se oponen a la enseñanza tradicional, expositiva y de carácter magistral en la que se reproducen los contenidos culturales aceptados tácitamente y acríticamente. Se piensa, analiza y realiza formas muy diversas de trabajo con acción directa en las comunidades. Es así como se han realizado, entre otras, las siguientes experiencias: 
Seminarios y Congresos nacionales e internacionales organizados y co-organizados; Foro con políticos jóvenes; Praxis Comunitaria desde una visión latinoamericana; Prácticas discursivas de niños, niñas, agentes institucionales y familia en contextos de vulnerados; Escuelas Alternativas; Seminario Nacional de Instituciones formadoras de Educadores/as de párvulos; Congreso Internacional de red de Semilleros de Antioquia; Congreso Nacional de Educación Parvularia; Laboratorio Cultural Alterativo; En defensa de la escuela; Creatividad, corporalidad y pedagogía lúdica; Taller de estudio de género; Fragilidad de la infancia; Encuentro de Nuestra América; entre otros.

\section{Algunas preguntas y algunas respuestas de nuestras semillas}

¿Qué es para nosotros/as el Semillero de investigación?

«Comprensión del pensamiento crítico»; «Valoración del desarrollo personal»; «Posibilidad de descubrir la propia potencialidad y actualizarla»; «Confianza en el propio potencial y en el trabajo en equipo»; «Innovación».

¿Como ha influido el semillero en cada una/o de nosotras/os?

«Para conocer diferentes experiencias y culturas»; «Descubrir el sentido de la Alteridad»; «Valorar la relevancia de la infancia, la natalidad y la hospitalidad permanente»; «Comprender la concepción intercultural de los derechos humanos».

¿Qué aportes hemos entregado al Semillero?

"Lazos de amistad y confianza»; «Ser un apoyo para otros/as integrantes del semillero»; «Trabajo en equipo»; «Crear posibilidades de resistencia y de alternativas contrahegemónicas»; «Reconocer la diversidad y las diferencias culturales».

¿Cómo me siento en el semillero?

«Reconocidas/os como actores sociales»; «Capaces de autogestión»; «Respetada/o en mi legitimidad»; «Con identidad»; «Contenta/o».

\section{Destacadas representaciones}

Las semillas han tenido destacada participación como ponentes y pasantes en experiencias tales como: Reunión Internacional de Semilleros en Bogotá, Colombia; I Congreso Internacional de Semilleros, Medellín, Colombia; Redes de ciudadanía, Belo Horizonte, Brasil; II Congreso Internacional de Semilleros. Bucaramanga, Colombia; I Bienal Latinoamericana de la Infancias y Juventudes «Democracias, Derechos Humanos y Ciudadanías», Manizales, Colombia; Universidad de Brasilia; Universidad de Antioquia, Colombia; Semilleros de Río Negro, Colombia, entre otras.

\section{Procesos y Logros}

Algunos logros de las/os semillas son los Coloquios ciudadanos (con obreros, madres de familia, vecinos, etc.) y académicos (profesores/as de la universidad y otros); Trabajos comunitarios de colaboración mutua para la mejora de espacios; Creación de bibliotecas; Apoyo a laboratorios culturales; Organización y participación en Seminarios nacionales e internacionales; Diálogos pedagógicos cotidianos; Publicación de la revista Semillas; Recepción de pasantes de diversos países latinoamericanos; Viaje a otros países latinoamericanos para enriquecer su propia cultura; Trabajos comunitarios; Partici- 
pación en actividades de la carrera de Pedagogía en Educación Parvularia de la ULS; Participación en la génesis del libro ¿Por qué ladran los perros? Epistemología infantil (López de Maturana, editora y compiladora, 2017); Creación de cuentos infantiles con un enfoque educativo; Entre otros...

\section{Pasantías}

El Semillero facilita la perspectiva Intercultural crítica a través de las pasantías a diferentes países, principalmente, latinoamericanos (Argentina, Brasil, Colombia, Ecuador, España, México, Puerto Rico), en donde actúan como embajadoras/es estudiantiles construyendo pedagogías; descubriendo sus capacidades y poniéndolas en juego; desarrollando Autoconfianza, Motivación de logro y Trabajo colaborativo; descubriendo la riqueza intercultural que les aleja del etnocentrismo; viajando al centro de sus preconcepciones... Todo generado a través de la autogestión y la solidaridad entre los mismos integrantes del grupo.

Los y las semillas han logrado conocer diferentes realidades, complementarse, generar lazos de amistad, confianza, crecimiento, confianza en el propio potencial, comprender a otros, trabajo en equipo y ser un apoyo para las/os nuevas/os integrantes del Semillero.

En consecuencia, el Semillero es un desafío profesional, ético y político para buscar líneas de acción orientadas a redefinir el compromiso estudiantil de quienes se están formando para ser formadores/as. Las/os semillas, entonces, se dan cuenta de la relevancia de su protagonismo estudiantil inmediato y de su protagonismo profesional futuro. Se preguntan por los niños y niñas que están dejando al mundo y se comprometen a co-construir una escuela que no se someta y que busque la dignidad, derechos y libertades de todas las personas.

\section{Semeadores de Investigação (Semillero Brasil): educación, trans- formación y alegría en la formación docente - Brasil}

Semillero Brasil surgió del encuentro con profesores, catedráticos y estudiantes chilenos de la Universidad de La Serena (ULS), especialmente con el profesor Carlos Calvo Muñoz y las profesoras Silvia López de Maturana y Yanola González Díaz, en 2015. Los procesos formativos promovidos por esta acción han ido transformándose y adquiriendo contornos interculturales y decoloniales en los últimos años. Su existencia proviene del rigor ético intercultural de las acciones formativas, del cuidado con las naturalezas, de la infancia, de las comunidades y de la extensión universitaria en la Universidad de Brasilia (UnB)/Brasil, ya que en la UnB está institucionalizada como un proyecto de extensión. Su labor está comprometida con una educación social activa y una pedagogía transformadora que, en la práctica, ratifica el principio del Buen Vivir y radicaliza la experiencia de las acciones de resistencia como herramientas de supervivencia y reinvención colectiva. La labor de este proyecto guarda una estrecha relación con la educación social (Freire, 1996; 2001) y la pedagogía decolonial (Walsh, 2017). Esto se refleja, por tanto, en la formación inicial de los estudiantes de pedagogía y de la comunidad que la constituye. 


\section{Formación de profesores, trabajo pedagógico con la infancia y acciones de $r$ - existencia.}

Nuestras acciones se dividen en tres direcciones: experiencias interculturales de formación, trabajo pedagógico de investigación con la infancia y prácticas de r-existencia. La construcción de cada una de ellas se llevó a cabo en reuniones de estudio, prácticas y reflexiones con todos los estudiantes y profesores que pasaron y se reúnen en Semillero. Semillas, que en otra lógica temporal, construyen cuidadosamente su camino/desarrollo a través de textos, personas, historias, escuelas, países y actividades diversas. Las características de la autogestión, la coordinación colegiada (profesores y estudiantes), la elección de dónde caminar, qué investigar, estudiar y cómo actuar están presentes en todas las reuniones. El trabajo colectivo da rigor y despliegue a las actividades planificadas.

\section{Experiencias interculturales de formación}

Nuestras reuniones semanales de coordinación colectiva, planificación de acciones y fortalecimiento del Buen Vivir del grupo y de la comunidad, se realizan con la presencia de los participantes, y su registro está en cuadernos construidos colectivamente, que representan una especie de Hypomnémata del semillero, donde construimos una estética propia de la existencia del Semillero. En ello, con palabras, dibujos, pinturas, collage, garabatos y fotos, tenemos el testimonio de nuestra existencia, en estos años de convivencia y trabajo en colaboración. La escritura como marca de una historia que ha sucedido en la circularidad del ir y venir de varios estudiantes que participan o ya han pasado por Semillero Brasil.

Los intercambios representan la radical experiencia pedagógica con otras culturas, para sembrar y volver a sembrar la vida desde las grietas y hendiduras (Walsh, 2017). Las experiencias interculturales vividas en los intercambios de estudiantes, acompañadas durante estos últimos cinco años, modifican, enriquecen, transforman y potencian la formación docente y reconfiguran nuestra posición con las infancias. La importancia de Semillero Brasil radica en la singularidad de potenciar, en el encuentro con los países latinoamericanos, el despliegue de experiencias similares $y$, paradójicamente, distintas en su impacto formativo para los estudiantes de licenciatura, considerando las culturas en las que se insertan, desde una perspectiva intercultural (Walsh, 2017; Quijano, 2000). En cada intercambio observamos que se crean y modifican ideas, proyectos y posiciones éticas en quienes viven, acogen y son acogidos en estas experiencias de intercambio y aprendizaje. Los miembros de los tres semilleros (presentados en este ensayo) ya han estado en los tres países y, visiblemente, hemos notado el efecto positivo de estos encuentros académicos y personales. Encuentros que se cambian en nuevas experiencias, prácticas pedagógicas y culturales.

\section{Trabajo pedagógico de investigación con la infancia}

Hemos llamado al trabajo de investigación con las infancias Semillas Encantadas, una expresión que, desde 2017, sintetiza el deseo radical de sembrar y resistir, y nuestro acercamiento a la cosmovisión de los pueblos originarios, en una referencia a los Encantados. Se trata de procesos autodirigidos (lo que no significa trabajo o procesos individuales o solitarios), la experiencia como posibilidad de estar en la investigación, la creación, la construcción de redes y el acceso al conocimiento a través de senderos y cami- 
nos. En esta acción, los niños de diferentes espacios educativos son acompañados por los estudiantes de Semillero, en procesos de investigación. El objetivo es despertar, con los niños, el encanto por los misterios de las cosas del mundo y la alegría de trazar pistas de investigación para desvelarlas (Calvo, 2013); transformar la curiosidad en una cuestión de investigación. Tanto en los espacios escolares como en los no escolares, públicos y privados, esta acción propone la valoración de los diferentes saberes e intereses de los niños, en una experiencia en la que la pedagogía de la pregunta está presente. En este sentido, los semilleros de investigación, se comprometen a una educación que rompa con las prácticas convencionales, buscando la protección de los derechos de los niños y la creación de espacios educativos alegres, donde cada uno pueda expresar su poder, perseguir sus preguntas, recorrer sus caminos hacia las respuestas y estudiar, estudiar, siempre. Semillas Encantadas tiene como objetivo el trabajo radical de las fortalezas, pasiones e inspiraciones investigativas de los niños. Su desarrollo en la escuela, en este caso, es la puerta de entrada para fortalecer los conocimientos tradicionales del territorio educativo en el cual se encuentran.

\section{Prácticas de r-existencia}

En esta dirección, el trabajo de Semillero se desarrolla en la organización, ejecución y participación en acciones que experimentan otras epistemes, prácticas inclusivas, innovadoras, transformadoras y decolonizadoras. El grupo colabora con varios eventos nacionales e internacionales, en América Latina, con el objetivo de integrar y promover el encuentro de proyectos y personas que apuntan a una educación centrada en la promoción de los derechos de los niños y niñas y la formación de profesores.

Las acciones locales, nacionales, internacionales e interculturales (intersaberes e interaprendizaje) para fortalecer los vínculos de América Latina (Abya Yala) con los diferentes grupos de Semilleros de Investigación, son siempre una prioridad. Con cada acción, una transformación de uno mismo y de los demás.

Como ejemplo, podemos destacar la I CONAÑINA que fue organizada y coordinada por el grupo Semillero, dentro del programa de la iv Conferencia Nacional de Alternativas para una Nueva Educación (CONANE), que tuvo lugar en Brasilia los días 20, 21 y 22 de junio de 2019. El objetivo de CONANIÑA fue promover un encuentro en el cual los niños pudieran compartir sus experiencias escolares y no escolares de diferentes prácticas educativas, así como iniciar una red de niñas y niños constructores de paz. Los ejes organizativos de CONANIÑA fueron:

- Territorio dialógico: reconocimiento radical por parte de los niños de cómo establecer o no los espacios dialógicos en las escuelas, dando sentido a la palabra colectiva e individual.

- Territorio educativo: la ciudad como espacio para ser ocupado por los niños, la comprensión del cuidado con las naturalezas y la discusión del especismo como guía para la comprensión de la construcción de un territorio educativo libre, plural y democrático.

- Cultura democrática: discusión y comprensión de cómo se lleva a cabo una gestión democrática en los espacios colectivos de trabajo con las infancias. Dispositivos de habla y escucha, asambleas, plenarias, entre otros. 
- Aprendizaje: socialización y puesta en común de diferentes formatos escolares y no escolares, organizaciones innovadoras y alternativas a los modelos actuales. Los niños informaron, debatieron y presentaron sus experiencias de aprendizaje y desarrollo en diferentes contextos.

- La construcción de la paz: en este espacio la propuesta principal era pensar en los sentidos y prácticas de la construcción de la paz en el territorio, la ciudad, el país y nuestra América. Cómo vivir y promover la paz en acciones de transformación y significado intercultural desde nuestras investigaciones.

- Mediación de conflictos: en un proceso de compartir experiencias de conflicto, vividas en sus espacios educativos, los niños socializaron las diferentes formas de eliminar las relaciones violentas y mejorar la escucha activa y la resolución de conflictos.

Esta experiencia organiza el significado de la capacitación de los educadores involucrados, los procesos de investigación de Semillas Encantadas y los movimientos de existencias que tienen la participación de Semillero Brasil como un hilo tejido en muchas manos.

\section{Semillero, semilla, sembradura}

Con cada actividad desarrollada por el Semillero, vivimos la experiencia de las verdades provisionales y somos motivados por el amor, la amistad y la esperanza, para sostener un espacio universitario que depende, exclusivamente, del deseo de cambio y de la comprensión social de estar en el campo de la educación. La libertad de pensar, de vivir, de aprender hasta el infinito, mantiene nuestro enfoque en una educación radicalmente social, la educación como transformación social y popular, comprometida con los principios de una pedagogía libertaria y el reconocimiento del protagonismo de los niños, niñas y jóvenes.

Nuestra organización hacia lo imposible, o sea, la resistencia al conservadurismo de algunas instituciones y la defensa de la infancia y de las naturalezas. Como afirma PortoGonçalves (2008), «[...] más que resistencia, lo que uno tiene es R-Existencia ya que no reacciona, simplemente la acción de otros, sino que algo preexiste y es de esta existencia que R-Existe» (p. 47). Existimos a través de encuentros que promueven el aprendizaje, la investigación y la construcción de un tiempo de siembra, que preserva y recupera la acción colectiva y la resignificación de nuestras historias latinas. Semillero Brasil está hecho por el joven poder de los estudiantes que lo apoyan y la convicción docente de mantener un espacio dialógico y formativo en la Universidad brasileña.

\section{Tesituras finales}

Considerando el contexto político de pérdida de derechos en América Latina, la discusión intercultural y la pedagogía decolonial surgen para darnos posibilidades de pensar en la resistencia desde la educación. Como educadoras, investigadoras y docentes, comprometidas con la vida, con la formación de maestros y con el aprendizaje de los niños y niñas, reconocemos en este enfoque teórico y práctico, en el que se constituye la acción de los Semilleros de Investigación, el camino hacia nuevas r-existencias pedagógicas que cohabiten para una transformación político-histórica, que ratifique otros epistemes y la defensa de una sociedad que tiene en sus pueblos originarios, en sus 
infancias y en la comprensión de la urgencia de proteger sus naturalezas, el objetivo primordial de nuestro encuentro académico, personal y político.

Finalizamos este artículo recordando que el encuentro de los Semilleros de Colombia, Chile y Brasil que reunió y fortaleció nuestro trabajo como investigadoras universitarias. Nuestras acciones de extensión universitaria se acercan cada día más en torno a proyectos comunitarios creativos, libres y posibles. El trabajo de los Semilleros va más allá de la formación investigativa, está en la tesitura de una Red Latinoamericana que se ha ido fortaleciendo con cada encuentro organizado por estos grupos, organizando así un nuevo pensamiento y una práctica continua del hacer en la educación.

\section{Referencias}

AA.VV. (1996) Colombia al filo de la oportunidad. Santafé de Bogotá, Presidencia de la República-COLCIENCIAS-Tercer Mundo Editores. Recuperado en 2 de abril, 2021, de de http://www.plandecenal.edu.co/cms/media/herramientas/colombia_al_filo_de_ la_oportunidad.pdf

Arendt, H. (2001) La condición humana. Buenos Aires, Paidós.

Bautista, J. J. (2014) ¿Qué significa pensar desde América latina? Madrid, Akal.

Calvo, C. M. (2013) Del mapa escolar al territorio educativo. Disoñando la escuela desde la educación. La Serena, Editora Universidad de La Serena.

Candau, V.M.F. y Russo, K. (2010) «Interculturalidade e educação na América latina: uma construção plural, original e complexa». Revista Diálogo Educação, núm. 29, v. 10, pp. 151-169.

Cortina, A. y Conill, J. (Ed.) (2001) Educar en la ciudadanía. València, Institució Alfons el Magnànim.

Chul Han, B. (2018) La expulsión de lo distinto. Barcelona, Herder.

Freire, P. (1972) Educación liberadora. Medellín, Ed. Prisma.

Freire, P. (1996) Pedagogia da Autonomia: saberes necessários à prática educativa. São Paulo, Paz e Terra.

Freire, P. (2001) Pedagogia dos sonhos possíveis. São Paulo, Ed. UNESP.

Freire, P. (2005) Educación como práctica de la libertad. México, Ediciones siglo xxi.

Gallón, L.F.M. (2009) Orígenes y dinámica de Los Semilleros de Investigación en Colombia - La visión de los Fundadores. Medellín, Universidad del CalcaUniversidad de Antioquia.

Hernández, E. (2017) Hasta que la dignidad se haga costumbre. https://ptbr.facebook.com/lajornadaonline/videos/hasta-que-la-dignidad-se-haga-

costumbre-estela-hernández/10155237113598706/ [Recuperado el 17 de marzo, 2021]

Lévinas, E. (2012) Totalidad e infinito. Salamanca, Ediciones Sígueme.

López de Maturana, S. (2016) Los buenos profesores: Educadores comprometidos con un proyecto educativo. La Serena, Editorial Universidad de La Serena.

López de Maturana, S. (Editora y compiladora) (2017) ¿Por qué ladran los perros? Epistemología infantil. La magia de las preguntas y respuestas de los niños. La Serena, Editorial Universidad de La Serena. 
López de Maturana, S. (2019) «Resacralizar la infancia: Complejidad y propensión del aprendizaje». En Videla, R. (editor) Pasos hacia una ecología cognitiva de la educación. La Serena, Editorial Universidad de La Serena, pp. 117-130.

Martínez Boom, A.; Noguera, C. E.; Castro, J. O. (1989) «Pedagogía, enseñanza de las ciencias y modelo curricular». Educación y cultura, núm. 17, pp. 17-23.

Montoya-Rodas, S. (2016) Autoanálisis de un semillerista germinante en Akará. Memorias del Encuentro Sennova. Rionegro, SENA, GIFOA y Gigaca.

Porto-Gonçalves, C. W. (2008) «De saberes e de territórios: diversidade e emancipação a partir da experiência latino-americana», en Ceceña, A. E. (Coord.) De los saberes de la emancipación y de la dominación. Buenos Aires, Consejo Latinoamericano de Ciencias Sociales-CLACSO, pp. 37- 52.

Quijano, A. (2000) «Colonialidad del poder y clasificación social». En Journal of worldsystems reserch, VI, 2, Summer/fall, pp 342-386. de http://www.ramwan.net/restrepo/poscolonial/9.2.colonialidad\%20del\%20poder\%2 0y\%20clasificacion\%20social-quijano.pdf [Recuperado en 12 de enero, 2021]

Rodari, G. (2016) La gramática de la fantasía. Barcelona, Editorial Planeta.

Rodrigues, F. L. V.; Ospina-Alvarado, M. C.; Alvarado, S. V.; Llanos-Erazo, D. (2019) «Una historia qué contar: encuentro de niños y niñas III Bienal Latinoamericana y Caribeña en Infancias y Juventudes "Desigualdades, Desafíos a la Democracia, Memorias y ReExistencias"». Revista latinoamericana de ciencias sociales, niñez y juventud, v.17, pp. $65-103$.

Serres, M. (1999) El tercero instruido. Medellín, Universidad Nacional de Colombia.

Serres, M. (2015) Figuras del pensamiento: autobiografía de un zurdo cojo. Barcelona, Gedisa.

Walsh, C. (2017) «Pedagogías Decoloniales». En Gutiérrez Alarcón, T. Convergencias y divergencias: hacia educaciones y desarrollo "otros". Bogotá, Corporación Universitaria Minuto de Dios-UNIMINUTO-Centro de Educación para el Desarrollo (CED), pp. 55-77.

Zemelman, H. (2007) El ángel de la historia: determinación y autonomía de la condición humana. Barcelona, Anthropos. 


\section{Semilleros de investigación a Colòmbia, Xile i Brasil: trobades pedagògi- ques, experiències i accions de r-existències en la formació docent}

Resum: En els darrers cinc anys s'ha dut a terme l'experiència transformadora dels Semilleros de investigación a Colòmbia, Xile i Brasil, centrada en la formació de joves universitaris, la creació d'espais d'investigació amb les infàncies i la pràctica transformadora del seu territori. Són tres realitats diferents $i$ amb propostes d'acció vinculades a universitats i accions que promouen altres r-existències a la nostra Abya Yala. L'objectiu principal d'aquest treball és compartir les diferents experiències de formació del professorat, derivades de la trobada intercultural de professors $i$ estudiants universitaris, que desitjaven oferir un espai alternatiu als plans d'estudis i recerca, en el sistema universitari. El text presenta, doncs, el registre d'aquestes accions i el camí indirecte que permet trobades pedagògiques transformadores i pràctiques decolonials, que donen suport a les accions i, paradoxalment, a les seves singularitats.

Paraules clau: planters d'investigació, interculturalitat, formació docent, accions de r-existència.

\section{Semilleros de investigación en Colombie, au Chili et au Brésil : rencontres pédagogiques, expériences et actions de r-existences dans la formation des enseignants}

Résumé: Au cours de ces cinq dernières années, nous avons suivi l'expérience transformatrice des Semilleros de investigación en Colombie, au Chili et au Brésil, axée sur la formation pédagogique des jeunes étudiants universitaires, la création d'espaces de recherche avec les enfants et la pratique transformatrice de leur territoire, trois réalités différentes et avec des propositions d'action liées aux universités et aux actions de promotion d'autres r-existences dans notre Abya Yala. L'objectif principal de cet essai est de partager les différentes expériences de formation des enseignants, issues de la rencontre interculturelle de professeurs et d'étudiants universitaires, qui ont souhaité offrir un espace alternatif aux programmes d'études et à la recherche académique. Le texte présente ainsi le bilan de ces actions et la voie indirecte qui permet des rencontres pédagogiques transformatrices et des pratiques décoloniales, qui soutiennent la communalité des faits et, paradoxalement, leurs singularités.

Mots-clés: Semilleros de investigación, interculturalité, formation des enseignants, actions de rexistences

\section{Seedbeds of investigation in Colombia, Chile and Brazil: pedagogical meet- ings, experiences and actions of r-existences in teacher training}

Abstract: Over the last five years we have followed the transformative experience of the Seedbeds of investigation in Colombia, Chile and Brazil, focused on the teaching formation of young university students, the creation of investigative spaces with childhood and the practices to transform their territory, three different realities and with proposals for action linked to the Universities and the actions promoting other r-existences in our own Abya Yala. The main objective of this essay is to share the different experiences of teacher education, arising from the intercultural meeting of university professors and students who wished to offer an alternative to academic teaching plans and research. The text presents the record of these actions and the indirect path that enables transformative teaching meetings and decolonial practices, which support the communality of the actions, and, paradoxically, their individual features.

Keywords: Seedbeds of investigation, interculturality, teacher training, actions of r-existences. 